\title{
Estimation of optimal area and volume for double arch-dams
}

\author{
Enrico Zacchei ${ }^{1, *}$, José Luis Molina ${ }^{1}$ \\ ${ }^{1}$ Higher Polytechnic School of Ávila, University of Salamanca (USAL), 50 Hornos Caleros Avenue, \\ 05003, Ávila, Salamanca, Spain
}

\begin{abstract}
This research is focused on the optimum area and volume estimation of double arch dams. The first stage of the methodology refers to defining issues about Bayesian estimators to obtain the value for designing the optimum dam shape. After that, the shape equations are iterated step-bystep to obtain the optimal solution. From the inventory of existing dams, it is possible to extract many important values although they are not sufficient. To obtain the non-available data, the Gaussian distribution under the Bayesian theorem hypotheses has been employed. This theorem converts the prior distribution using unknown parameters into the posterior distribution which provides expected estimators. The choice of the dam shape is strongly based on the experience, therefore by knowing and applying real information of existing dams it is possible to carry out a more precise analysis.
\end{abstract}

\section{Introduction}

Among the existing stochastic methods, the Bayesian method is of great interest in Engineering fields such as hydraulic engineering, to calculate the probability and analyse the risk of a reservoir collapse [1], structural engineering, to define the elastic modulus and the structural period [2] or in the field of earthquake engineering to estimate the extreme earthquake occurrence [3], which is necessary to design the structure.

Bayesian theorem is useful when the analysis comprises a lot of parameters. The enormous quantity of variables that each project contains and the necessity to find the worst probable scenario, make that nowadays probabilistic methods are used more over the time.

The general idea of this paper is to estimate the necessary values to define the best volume and area in terms of concrete quantity for double arch-dams. The objective is to minimize the concrete volume and the area of double arch dams.

The variables to calculate the shape optimization have been estimated by using the Bayesian theorem. This theorem can be used when some information about the statistical distribution are known.

The Bayesian distribution adopts the Gaussian normal distribution where the mean value is supposed a priori. A normal distribution of this type is called prior distribution of Bayesian estimators [4]. To use the prior distribution, it is necessary to obtain some information about

\footnotetext{
* Corresponding author: enricozacchei@usal.es
} 
the random variables, in particular it is necessary to know their intervals for defining a maximum and minimum value.

\section{Bayesian distribution}

The Bayesian distribution is here applied to calculate the volume and area of double arch dams. From literature, five papers have been considered [5-9] and the values of the results in these works have been used to develop the Bayesian theorem. The samples are formed by 770 collected date. The Bayesian estimators are calculated from prior distribution and posterior distribution. The values in the prior distribution refer to an existing dam whereas the values of the posterior distribution refer to an optimum dam. The analysis consists in changing the parameters of an existing dam to obtain the parameters for an optimum dam.

In statistical terms, the prior distribution for existing dams $\theta \sim N\left(\mu, \sigma^{2}\right)$ pass to the posterior distribution for optimized dams $\theta \sim \mathrm{N}\left(\mu_{\mathrm{p}}, \sigma_{\mathrm{p}}^{2}\right.$ ), where $\mu$ and $\sigma^{2}$ are the mean and the variance of the Probability Density Function (PDF) a priori and $\theta$ is the unknown parameter. The expected value a posteriori and the variance a posteriori are, respectively:

$$
\begin{gathered}
\mu_{p}=\frac{n / \sigma_{0}^{2}}{n / \sigma_{0}^{2}+1 / \sigma^{2}} \bar{x}+\frac{1 / \sigma^{2}}{n / \sigma_{0}^{2}+1 / \sigma^{2}} \mu \\
\sigma_{p}^{2}=\frac{1}{n / \sigma_{0}^{2}+1 / \sigma^{2}}
\end{gathered}
$$

where $\sigma_{0}^{2}$ is the known variance, $\bar{x}$ is the sample mean and $\mathrm{n}$ is the number of the sample.

With these values it is possible define the PDF a posteriori and the PDF a priori. PDF is expressed by a Gaussian Normal (N) distribution.

Table 1 shows the results where $\sigma$ and $\sigma_{\mathrm{p}}$ are the standard deviations of each variable calculated, using the 84-percentile.

Table 1. Data of the analysis of the distribution a priori and a posteriori.

\begin{tabular}{cccccc}
\hline Variable & $\boldsymbol{\mu}$ & $\boldsymbol{\sigma}$ & $\boldsymbol{\mu}_{\mathbf{p}}$ & $\boldsymbol{\sigma}_{\mathbf{p}}$ & Interval of $\boldsymbol{\mu}_{\mathbf{p}}{ }^{*}$ \\
\hline $\mathrm{t}_{1}$ & 7.49 & \pm 6.55 & 6.38 & \pm 0.35 & $5.80-6.97$ \\
$\mathrm{t}_{2}$ & 12.23 & \pm 6.37 & 12.96 & \pm 0.33 & $12.40-13.53$ \\
$\mathrm{t}_{3}$ & 23.50 & \pm 18.93 & 28.67 & \pm 1.02 & $26.98-30.36$ \\
rUS1 $_{\text {rUS2 }}$ & 125.56 & \pm 38.94 & 114.91 & \pm 2.11 & $111.44-118.38$ \\
rUS3 & 78.21 & \pm 23.47 & 86.75 & \pm 1.27 & $84.66-88.85$ \\
rUS3 & 31.19 & \pm 16.81 & 37.00 & \pm 0.91 & $35.50-38.49$ \\
rDS1 & 87.68 & \pm 43.88 & 101.59 & \pm 2.37 & $97.68-105.50$ \\
rDS2 & 65.08 & \pm 32.98 & 78.71 & \pm 1.79 & $75.77-81.65$ \\
rDS3 & 30.37 & \pm 13.88 & 33.59 & \pm 0.75 & $32.36-34.83$ \\
$\mathrm{~S}$ & 0.20 & \pm 0.22 & 0.25 & \pm 0.00 & $0.2-0.28$ \\
$\beta$ & 0.75 & \pm 0.52 & 0.78 & \pm 0.00 & $0.74-0.83$ \\
\hline
\end{tabular}

*Interval of the $\mu_{\mathrm{p}}$ using the 90 -percentile.

All variables are expressed in meter excepting the variables $\mathrm{s}$ and $\beta$, which are adimensional. The 11 design variables are explained later on. The vertical and horizontal shape is divided in three level. The subscripts in the design variables indicate the level 1, 2 and 3 . 


\section{Geometrical model analyses}

The geometrical model is divided in two parts: vertical and horizontal section (see Figure 1). The equations developed in three dimensions $\mathrm{x}, \mathrm{y}$, and $\mathrm{z}$ describe the internal and external surfaces as well as the dam thickness. In the model described in literature [5] the geometrical characteristics of the sections, the behaviour constraints due to the frequency mode of the dam, the stress of the internal force and the stability have been considered. But, in this analysis only geometric and stability constraints have been used.

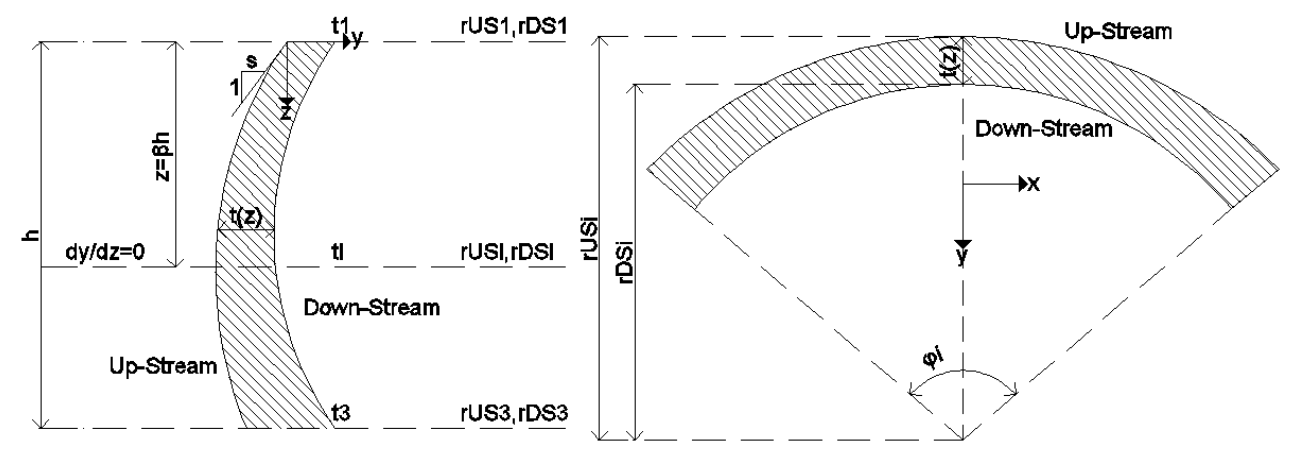

Fig. 1. Vertical and horizontal sections drawing by software [10]. Note: the flow of the water goes from Up-Stream (US) to Down-Stream (DS) face.

Double arch dams are defined by following equations. The function that defines the volume $\mathrm{v}(\mathrm{x}, \mathrm{z})$ is:

$$
v(x, z)=\iint\left|y_{D S}(x, z)-y_{U S}(x, z)\right| d x d z
$$

where in order that $\mathrm{v}(\mathrm{x}, \mathrm{z})>0$ the absolute value $|\cdot|$ is introduced. The area $\mathrm{a}(\mathrm{x}, \mathrm{z})$, defined as the sum of the areas of the US and DS faces, is:

$$
a(x, z)=\iint \sqrt{1+\left(\frac{d y_{U S}}{d x}\right)^{2}+\left(\frac{d y_{U S}}{d z}\right)^{2}} d x d z+\iint \sqrt{1+\left(\frac{d y_{D S}}{d x}\right)^{2}+\left(\frac{d y_{D S}}{d z}\right)^{2}} d x d z
$$

where yus and yDs are the shape of the horizontal section at the US and DS face defined by, respectively:

$$
\begin{gathered}
y_{U S}(x, z)=\frac{1}{2 r_{U S}(z)} x^{2}+y(z) \\
y_{D S}(x, z)=\frac{1}{2 r_{D S}(z)} x^{2}+y(z)+t(z)
\end{gathered}
$$

whit $y(z)=-s z+s z^{2} / 2 \beta h$, where $\mathrm{s}$ is the slope at the crest and $\mathrm{h}$ is the height of the dam related to the ratio $\beta=\mathrm{z} / \mathrm{h}$. $\mathrm{r}_{\mathrm{US}}$ and $\mathrm{r}_{\mathrm{DS}}$ are the radii of curvature of the US and DS curve, respectively, and $\mathrm{t}(\mathrm{z})$ is the thickness of the central vertical section.

The region of integration in the Eqs. 3-4 is produced by projecting the dam on $\mathrm{x}-\mathrm{z}$ plane. The equations have been iterated step-by-step by the software [11].

The type of the design constraints about the behaviour, geometric, stability and stress have been shown in Table 2, which explains their utility and relation. The superscript $U$ and L mean upper bound and lower bound.

During the equations implementation, it is necessary to verify the constraints. From collected data in literature [5-9] and considering the results of the distribution posteriori (Table 1), it is possible to verify some constraints: $3.1 \leq \mathrm{t}_{1} \leq 11.9,8.0 \leq \mathrm{t}_{2} \leq 16.4,12.0 \leq \mathrm{t}_{3} \leq$ 
35.0. The maximum values of the slope $\mathrm{s}$ and the ratio $\beta$ are 0.36 and 1.0 , respectively. The constraints $r_{D S i} \leq r_{U S i}$ and $t_{i} \leq t_{i+1}$ can be verified by comparing the values in Table 1 .

Table 2. Design constraints.

\begin{tabular}{|c|c|c|}
\hline Type & Relation & Utility \\
\hline Behaviour & $\mathrm{f}_{\mathrm{i}}^{\mathrm{L}_{\mathrm{i}}} \leq \mathrm{f}_{\mathrm{i}} \leq \mathrm{f}_{\mathrm{i}}^{\mathrm{U}_{\mathrm{N}}}$ & $\begin{array}{c}\text { Dam frequency }\left(\mathrm{f}_{\mathrm{i}}\right) \text { depends on water, sediments and foundation } \\
\text { interaction }\end{array}$ \\
\hline Geometric & $\begin{aligned} & \mathrm{rDSi} \leq \mathrm{rUSi} \\
& \mathrm{s} \leq \mathrm{s}^{\mathrm{U}} \\
& \beta \leq \beta^{\mathrm{U}} \\
& \mathrm{t}^{\mathrm{L}} \leq \mathrm{t}_{\mathrm{i}} \leq \mathrm{t}^{\mathrm{U}} \\
& \mathrm{t}_{\mathrm{i}} \leq \mathrm{t}_{\mathrm{i}+1}\end{aligned}$ & $\begin{array}{l}\text { Radii of curvature prevent the intersection of the DS and US face } \\
\text { The slope helps the construction of the structure } \\
\text { This parameter changes the vertical curvature } \\
\text { The thickness defines a slender or squat dam } \\
\text { The thickness must be growing along the height }\end{array}$ \\
\hline Stability & $\varphi^{\mathrm{L}} \leq \varphi_{\mathrm{i}} \leq \varphi^{\mathrm{U}}$ & $\varphi_{\mathrm{i}}$ governs the sliding of the dam-foundation and dam-abutments \\
\hline Stress & $\begin{array}{l}\sigma_{c} \leq k_{d} f_{c} \\
\sigma_{t} \leq k_{d} f_{t}\end{array}$ & $\begin{array}{l}\text { Compressions must be limited during the construction and service } \\
\text { Tensile must be limited to avoid cracks in the dam body }\end{array}$ \\
\hline
\end{tabular}

To implement the equation, an ideal dam with the height of $95.55 \mathrm{~m}$ and the maximum crown length $L$ of $215.0 \mathrm{~m}$ have been adopted. $\mathrm{L}$ has been obtained by: $\mathrm{L}_{\mathrm{i}}=\mathrm{r}_{\mathrm{ai}} \mathrm{X} \varphi_{\mathrm{i}}$, whit $\mathrm{r}_{\mathrm{ai}}$ $=r_{U S i}-\left(t_{i} / 2\right)$, where $r_{a i}$ is the radius of the dam axis at level $\mathrm{i}$. For $\varphi_{i}=110^{\circ}(1.919 \mathrm{rad}) \mathrm{L}_{1}=$ $214.0 \mathrm{~m} \rightarrow 215.0 \mathrm{~m}, \mathrm{~L}_{2}=154.0 \mathrm{~m} \rightarrow 155.0 \mathrm{~m}$ and $\mathrm{L}_{3}=44.0 \mathrm{~m} \rightarrow 45.0 \mathrm{~m} \mathrm{[12]}$.

Dam are very rigid structure, therefore the dam frequency can be considered more than $3.33 \mathrm{~Hz}$ (period > $0.30 \mathrm{~s}$ ). Considering the whole system (dam-water-foundation-sediments) the period increases.

The allowed compression $\left(\sigma_{\mathrm{c}}\right)$ and tensile stresses $\left(\sigma_{t}\right)$ are defined in the design and they depend on $\mathrm{f}_{\mathrm{c}}$ and $\mathrm{f}_{\mathrm{t}}$, which are the compressive and tensile strength for concrete, respectively. Stresses in the dynamic analysis must also include the incremental load $\mathrm{k}_{\mathrm{d}}$.

Figures 2-4 show the optimum shape of the dam for the mean value of the distribution a posteriori and its errors $\left( \pm \sigma_{\mathrm{p}}\right)$ in three dimensions $\mathrm{x}, \mathrm{y}$ and $\mathrm{z}$. $\mathrm{x}$-axis represents the length of the dam, $y$-axis the radius and z-axis the height. The difference between US and DS face is the thickness. The height is partial because three blocks of $31.85 \mathrm{~m}$ have been considered. The shape in Figures 2-4 represents the mean section. The statistical errors are very little therefore it is not possible to see the variation in the shapes. The analysis has been made for three lengths L, i.e. $215.0 \mathrm{~m}, 155.0 \mathrm{~m}$ and $45.0 \mathrm{~m}$.
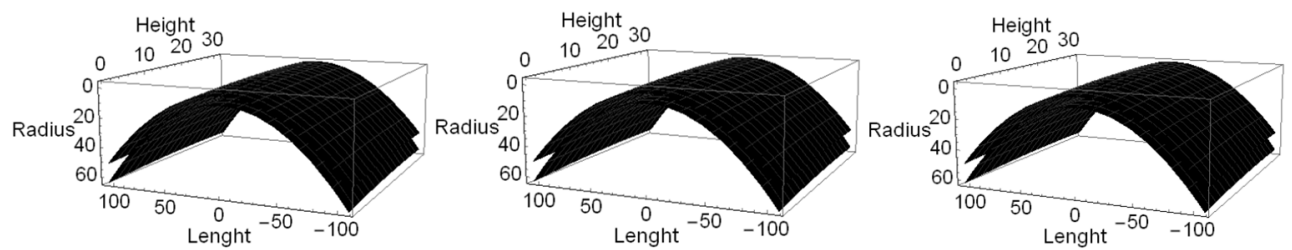

Fig. 2. Shape optimization $\left(\mathrm{L}_{1}=215.0 \mathrm{~m}\right)$ for $\mu_{\mathrm{p}}-\sigma_{\mathrm{p}}$ (left), $\mu_{\mathrm{p}}$ (centre), $\mu_{\mathrm{p}}+\sigma_{\mathrm{p}}$ (right).
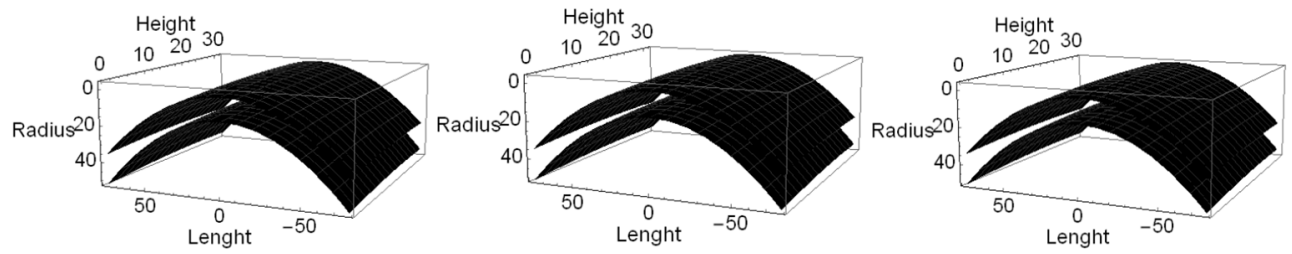

Fig. 3. Shape optimization $\left(\mathrm{L}_{2}=155.0 \mathrm{~m}\right)$ for $\mu_{\mathrm{p}}-\sigma_{\mathrm{p}}$ (left), $\mu_{\mathrm{p}}$ (centre), $\mu_{\mathrm{p}}+\sigma_{\mathrm{p}}$ (right). 

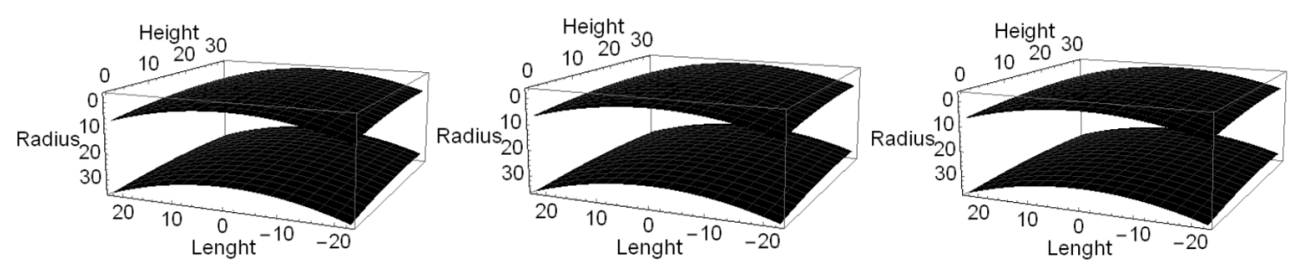

Fig. 4. Shape optimization $\left(\mathrm{L}_{3}=45.0 \mathrm{~m}\right)$ for $\mu_{\mathrm{p}}-\sigma_{\mathrm{p}}$ (left), $\mu_{\mathrm{p}}$ (centre), $\mu_{\mathrm{p}}+\sigma_{\mathrm{p}}$ (right).

Table 3 shows the results in terms of the concrete volume and area of the dam by using the distribution a posteriori.

Table 3. Results of the analysis.

\begin{tabular}{ccccccc}
\hline & \multicolumn{3}{c}{ Concrete volume $\left(\mathbf{m}^{3}\right)$} & \multicolumn{3}{c}{ Concrete area $\left(\mathbf{m}^{\mathbf{2}}\right)$} \\
\cline { 2 - 7 } Length $(\mathbf{m})$ & $\boldsymbol{\mu}_{\mathbf{p}}-\boldsymbol{\sigma}_{\mathbf{p}}$ & $\boldsymbol{\mu}_{\mathbf{p}}$ & $\boldsymbol{\mu}_{\mathbf{p}}+\boldsymbol{\sigma}_{\mathbf{p}}$ & $\boldsymbol{\mu}_{\mathbf{p}}-\boldsymbol{\sigma}_{\mathbf{p}}$ & $\boldsymbol{\mu}_{\mathbf{p}}$ & $\boldsymbol{\mu}_{\mathbf{p}}+\boldsymbol{\sigma}_{\mathbf{p}}$ \\
\hline $0-215.0$ & 57373.9 & 58737.7 & 60166.2 & 15890.6 & 15812.2 & 15738.2 \\
$0-155.0$ & 68783.3 & 69799.3 & 70855.5 & 11295.8 & 11250.1 & 11206.7 \\
$0-45.0$ & 39960.8 & 41423.1 & 42885.0 & 3081.98 & 3073.66 & 3065.86 \\
\hline Total $=$ & 166118.0 & 169960.1 & 173906.7 & 30268.4 & 30136.0 & 30010.8 \\
\hline
\end{tabular}

The concrete area for the $\mu_{\mathrm{p}}-\sigma_{\mathrm{p}}$ is greater than $\mu_{\mathrm{p}}+\sigma_{\mathrm{p}}$ due to the reduction of the internal and external curvature. The optimum volume and area have the probability of $68.26 \%$ for belonging to the following set $166118.0 \mathrm{~m}^{3} \leq\left.\mathrm{v}(\mathrm{x}, \mathrm{z})\right|_{\mu \mathrm{p}} \leq 173906.7 \mathrm{~m}^{3}$ and $30268.4 \mathrm{~m}^{2} \leq$ $\left.\mathrm{a}(\mathrm{x}, \mathrm{z})\right|_{\mu \mathrm{p}} \leq 30010.8 \mathrm{~m}^{2}$, respectively. The maximum error can be estimated in $3946.6 \mathrm{~m}^{3}$ for the volume and $132.4 \mathrm{~m}^{2}$ for the area.

The volume of the dam in respect to the dam area increases up to a certain value and then decreases. This is because the ratio of the crown length and thickness change, i.e. at the beginning the crown length ratio $215 / 155=1.38$ is lower than the thickness ratio $t_{2} / t_{1}=$ $12.96 / 6.38=2.03$, whereas at the end the ratio $155 / 45=3.44$ is greater than the ratio $t_{3} / t_{2}=$ $28.67 / 12.96=2.21$.

Considering the double arch dams with height 89.0 - $100.5 \mathrm{~m}$ taken from the inventory of the Spanish dams [13,14], the mean volume is $244250.0 \mathrm{~m}^{3}$. From this value, in this study the volume can be reduced from $29 \%$ to $32 \%$.

\section{Conclusions}

In this paper the optimal concrete volume and area for double arch dams has been calculated. The objective is to find the minimum volume and so the minimum area respecting some constraints, e.g. vibration mode of the dam, global geometry, stability of the dam body and constitutive relations of the material.

The Bayesian theorem has been successfully applied because enough data have been found, among other reasons. The equations have been iterated step-by-step easily.

The concrete volume reduction of the dam has been obtained and consequently, a reduction of the costs is expected. In this study the expected reduction of the volume is of around $30 \%$.

The authors are developing these theories and tools aimed to improve their use. Future research is planned to be published and patented.

The first author acknowledges the "Servicios Informáticos CPD" of the University of Salamanca for the Wolfram Mathematica license and the University of Salamanca to pay the rights (when applicable) to completely download all the references. 


\section{References}

[1] P. Li, C. Liang, Math. Probl. Eng., 2016, 1 (2016)

[2] G. Bartoli, M. Betti, L. Facchini, A.M. Marra, S. Monchetti, Proc. Eng., 199, 1258 (2017)

[3] K.W. Campbell, Bull. Seismo. Soc. Ame., 72, 1689 (1982)

[4] S.M. Ross, Probability and Statistics for Engineers and Scientists (Apogeo, Italy, 2008)

[5] A. Kaveh, R. Ghaffarian, I. J. Civ. Eng., 13, 1 (2014)

[6] A. Saber Mahani, S. Shojaee, E. Salajegheh, M. Khatibinia, App. Soft Comp., 27, 205 (2015)

[7] S.M. Seyedpoor, J. Salajegheh, E. Salajegheh, App. Math. Mod., 34, 1149 (2010)

[8] S. Gholizadeh, S.M. Seyedpoor, Scie. Iran. A, 18, 1020 (2011)

[9] D. Hamidian, S.M. Seyedpoor, App. Math. Mod., 34, 1574 (2010)

[10] AutoCAD, Version 2010, Autodesk, Inc. (2010)

[11] Wolfram Mathematica, Version 11 Student Edition, Wolfram Research, Inc (2017)

[12] U.S. Army Corps of Engineers (USACE), Arch Dan Design (Manual No. 1110-2-2201, Washington, D.C., USA, 1994)

[13] Inventory of Dams and Reservoirs (SNCZI), http://sig.mapama.es/snczi/visor.html (2017)

[14] Spanish Association of Dams and Reservoirs (SEPREM), http://www.seprem.es/index.php (2017) 